\title{
Overweight, obesity and risk of liver cancer: a meta-analysis of cohort studies
}

\author{
SC Larsson ${ }^{*, 1}$ and A Wolk' \\ 'Division of Nutritional Epidemiology, The National Institute of Environmental Medicine, Karolinska Institutet, PO Box 21 0, Stockholm SE- I 7 I 77 , Sweden
}

\begin{abstract}
Cohort studies of excess body weight and risk of liver cancer were identified for a meta-analysis by searching MEDLINE and EMBASE databases from 1966 to June 2007 and the reference lists of retrieved articles. Results from individual studies were combined using a random-effects model. We identified I I cohort studies, of which seven on overweight (with a total of 5037 cases) and I 0 on obesity (with 6042 cases) were suitable for meta-analysis. Compared with persons of normal weight, the summary relative risks of liver cancer were 1.17 (95\% confidence interval (Cl): 1.02- 1.34) for those who were overweight and 1.89 (95\% Cl: I.5I-2.36) for those who were obese. This meta-analysis finds that excess body weight is associated with an increased risk of liver cancer.
\end{abstract}

British Journal of Cancer (2007) 97, I005- 1008. doi: I0.1038/sj.bjc.6603932 www.bjcancer.com

Published online 14 August 2007

(c) 2007 Cancer Research UK

Keywords: body mass index; cohort studies; liver cancer; meta-analysis; obesity; review

Although relatively rare in the United States and other developed countries, liver cancer is the third most common cause of death from cancer worldwide (Parkin et al, 2005). It is rarely detected early and is often fatal within a few months of diagnosis. The 5-year survival rate is only about $6-11 \%$ (Coleman et al, 2003; Ries et al, 2006). The age-adjusted incidence and mortality rates of liver cancer have been increasing rapidly in the United States since the mid-1980s (Ries et al, 2006). While approximately half of this increase can be attributable to hepatitis $C$ virus infection, a minimal or no increase has been related to hepatitis B virus and alcoholic liver disease (El-Serag and Mason, 2000; Hassan et al, 2002). Given that about half of the increase in liver cancer incidence is not related to hepatitis, the major risk factor in a significant proportion of the cases has yet to be identified.

Coinciding with the rising incidence of liver cancer, the prevalence of obesity has been increasing markedly over the past two decades worldwide (Larsson and Wolk, 2006). Obesity has been recognised as a risk factor for several malignancies, including cancer of the breast (in premenopausal women), endometrium, kidney (renal cell), colon, pancreas, gallbladder, and esophagus (adenocarcinoma) (IARC, 2002; Larsson et al, 2007; Larsson and Wolk, 2007). Accumulating epidemiologic evidence also indicates that excess body weight may be a risk factor for liver cancer, but the evidence has not been quantitatively summarised. We have therefore quantitatively assessed the associations of overweight and obesity with liver cancer risk in a meta-analysis of cohort studies.

*Correspondence: Dr SC Larsson; E-mail: susanna.larsson@ki.se Received 13 June 2007; revised 12 July 2007; accepted 17 July 2007; published online 14 August 2007

\section{MATERIALS AND METHODS}

\section{Study selection}

A literature search was conducted in the MEDLINE and EMBASE databases for pertinent studies published in any language from 1966 to June 2007 . We used the keywords 'body mass index', 'BMI', or 'obesity' in combination with 'hepatocellular carcinoma', 'liver cancer', or 'liver neoplasm'. Moreover, we manually reviewed the reference lists of retrieved articles to search for more studies.

Studies were included in the meta-analysis if they fulfilled the following criteria: (1) cohort study in which liver cancer incidence or mortality was an outcome; (2) the exposure of interest was overweight and/or obesity defined by body mass index (BMI) (the weight in kilograms divided by the square of height in meters); and (3) relative risk estimates (rate ratio or standardized incidence ratio) with corresponding $95 \%$ confidence intervals (CIs) were reported.

\section{Data extraction}

For each study, the following information was extracted: first author's last name; publication year; country in which the study was performed; sample size; method of assessing weight and height; type of outcome (incidence or mortality); variables adjusted for in the analysis; and the relative risks with 95\% CIs for overweight and obesity vs normal weight. From each study, we extracted the most fully adjusted relative risks.

\section{Statistical analysis}

The relative risks and corresponding standard errors (derived from the CIs) from individual studies were logarithmically transformed to stabilize variances and normalize the distributions. We calculated summary relative risks for overweight (defined as 
BMI $25-30 \mathrm{~kg} \mathrm{~m}^{-2}$ ) and obesity (BMI $\geqslant 30 \mathrm{~kg} \mathrm{~m}^{-2}$ ) vs normal weight (BMI 18.5-24.9 $\mathrm{kg} \mathrm{m}^{-2}$ ). For two studies (Calle et al, 2003; Kuriyama et al, 2005) that reported relative risks for two categories of BMI that fell into the category representing overweight or obesity, we pooled the relative risks and used the pooled estimate in the meta-analysis. Study-specific relative risks were combined using the DerSimonian and Laird random-effects model (DerSimonian and Laird, 1986). Thus, each summary relative risk was a weighted average of the study-specific relative risk, where the weight for each study is the inverse of the sum of the within-study variance for that study, and the between-study variance.

Statistical heterogeneity among studies was evaluated with the $Q$ and $I^{2}$ statistics (Higgins and Thompson, 2002). For the $Q$ statistic, statistical significance was set at $P<0.1$. We used funnel plots (i.e. plots of study results against precision) to assess publication bias, and tested the symmetry of the funnel plot using Egger's test (Egger et al, 1997).

Results are presented graphically, whereby squares represent study-specific relative risks and diamonds represent summary relative risks. The area of each square is proportional to the inverse of the variance of the logarithm of the relative risk; $95 \%$ CIs for individual studies are represented by horizontal lines and for the summary estimates by the width of the diamonds. Statistical analyses were performed with Stata, version 9.0 (StataCorp, College Station, TX, USA).

Population attributable risk (PAR) for liver cancer was estimated for individuals with excess body weight $\left(\mathrm{BMI} \geqslant 25 \mathrm{~kg} \mathrm{~m}^{-2}\right)$ compared to those of normal weight $\left(\mathrm{BMI}<25 \mathrm{~kg} \mathrm{~m}^{-2}\right)$. The PAR describes the theoretic proportion of cases that would be prevented if all individuals were moved into the exposure level associated with the lowest risk for that factor. The PAR (PAR\%) was calculated as: $\mathrm{PAR} \%=(p \times[\mathrm{RR}-1] /$ $[p \times(\mathrm{RR}-1)+1]) \times 100 \%$, where $p$ represents the prevalence in the population and RR the relative risk. Prevalence data were obtained from the National Health and Nutrition Examination Survey that assessed the prevalence of overweight and obesity in a representative sample of the US population (Ogden et al, 2006). In that survey, $39.7 \%$ of the men were overweight and $31.1 \%$ were obese. Among women, $28.6 \%$ were overweight and $33.2 \%$ were obese. PARs were calculated for the overweight and obese categories using the obtained summary relative risks, and then summarized across the two categories for men and women separately.

\section{RESULTS}

We identified 11 eligible cohort studies (Møller et al, 1994; Wolk et al, 2001; Nair et al, 2002; Calle et al, 2003; Samanic et al, 2004, 2006; Batty et al, 2005; Kuriyama et al, 2005; Oh et al, 2005; Rapp et al, 2005; N'Kontchou et al, 2006), of which 7 on overweight (with a total of 5037 cases) (Calle et al, 2003; Batty et al, 2005; Kuriyama et al, 2005; Oh et al, 2005; Rapp et al, 2005; N'Kontchou et al, 2006; Samanic et al, 2006) and 10 on obesity (with a total of 6042 cases) (Møller et al, 1994; Wolk et al, 2001; Nair et al, 2002; Calle et al, 2003; Samanic et al, 2004, 2006; Batty et al, 2005; Oh et al, 2005; Rapp et al, 2005; N'Kontchou et al, 2006) were suitable for metaanalysis. Characteristics of the studies are shown in Table 1. Seven studies were conducted in Europe, two in the United States, and two in Asia. Weight and height were measured in six studies and self-reported in two studies; in three studies, obesity was defined by a discharge diagnosis of obesity. The outcome was incidence of liver cancer in all but two studies (Calle et al, 2003; Batty et al, 2005 ) in which the outcome was mortality from liver cancer. Two studies were based on standardized incidence ratio (Møller et al, 1994; Wolk et al, 2001). Two studies consisted of patients with cirrhosis (Nair et al, 2002; N'Kontchou et al, 2006).

Relative risks of liver cancer for overweight and obese individuals compared to those of normal weight for individual studies (separately for men and women wherever this data were available) and all studies combined are shown in Figure 1. Metaanalysis of all studies found that compared to individuals with normal weight, those who were overweight or obese had a 17 and $89 \%$, respectively, increased risk of liver cancer. There was statistically significant heterogeneity among the results of individual studies (Figure 1). The summary relative risk for obesity was statistically significantly higher $(P=0.03)$ for men (RR: $2.42 ; 95 \%$ CI: $1.83-3.20 ; n=7$ studies) than for women (RR: $1.67 ; 95 \% \mathrm{CI}$ :

Table I Characteristics of cohort studies included in the meta-analysis

\begin{tabular}{|c|c|c|c|c|c|}
\hline Study & Country & $\begin{array}{l}\text { No. of cases } \\
\text { (men/women) }\end{array}$ & Study participants & $\begin{array}{l}\text { Assessment of } \\
\text { exposure }\end{array}$ & Adjustments \\
\hline Møller et al (1994) & Denmark & $22 / 36$ & $\begin{array}{l}\text { Men: } 14531 \\
\text { Women: } 29434\end{array}$ & $\begin{array}{l}\text { Discharge diagnosis of } \\
\text { obesity }\end{array}$ & Age \\
\hline Wolk et al (200I) & Sweden & $15 / 13$ & $\begin{array}{l}\text { Men: } 8165 \\
\text { Women: } 19964\end{array}$ & $\begin{array}{l}\text { Discharge diagnosis of } \\
\text { obesity }\end{array}$ & Age, calendar year \\
\hline Nair et al (2002) & USA & $659^{a}$ & Men and women: $19271^{a}$ & Measured & Age, sex, race, diabetes \\
\hline Calle et al (2003) & USA & $620 / 345$ & $\begin{array}{l}\text { Men: } 404576 \\
\text { Women: } 495477\end{array}$ & Self-reported & $\begin{array}{l}\text { Age, race, education, marital status, smoking, } \\
\text { physical activity, aspirin use, estrogen-replacement } \\
\text { therapy (women), alcohol, dietary factors }\end{array}$ \\
\hline Samanic et al (2004) & USA & $\begin{array}{l}322 \text { whites/38 } \\
\text { blacks }\end{array}$ & $\begin{array}{l}\text { White men: } 3668486 \\
\text { Black men: } 832214\end{array}$ & $\begin{array}{l}\text { Discharge diagnosis of } \\
\text { obesity }\end{array}$ & Age, calendar year \\
\hline Kuriyama et al (2005) & Japan & $69 / 31$ & $\begin{array}{l}\text { Men: } 12485 \\
\text { Women: } 15054\end{array}$ & Self-reported & $\begin{array}{l}\text { Age, type of health insurance, smoking, intakes of } \\
\text { alcohol, meat, fish, fruits, vegetables, bean-paste } \\
\text { soup }^{\text {b }}\end{array}$ \\
\hline Batty et al (2005) & UK & 51 & Men: 18403 & Measured & $\begin{array}{l}\text { Age, employment grade, marital status, physical } \\
\text { activity, smoking, other }{ }^{c}\end{array}$ \\
\hline Oh et al (2005) & Korea & 3347 & Men: 78। 283 & Measured & $\begin{array}{l}\text { Age, area of residence, family history of cancer, } \\
\text { smoking, exercise, alcohol }\end{array}$ \\
\hline Rapp et al (2005) & Austria & 57 & Men: 67447 & Measured & Age, occupational group, smoking \\
\hline N'Kontchou et al (2006) & France & $220^{\mathrm{a}}$ & Men and women: $771^{\mathrm{a}}$ & Measured & Age, sex, cirrhosis cause, diabetes \\
\hline Samanic et al (2006) & Sweden & 297 & Men: 362552 & Measured & Age, smoking \\
\hline
\end{tabular}

a Patients with cirrhosis. ${ }^{b}$ Odds ratios for women were further adjusted for age at menarche, age at end of first pregnancy, and menopausal status. ${ }^{\circ}$ Other factors adjusted for include disease at entry, weight loss in the last year, height-adjusted FEV 1 , triceps skinfold thickness, blood pressure-lowering medication, blood pressure, plasma cholesterol, glucose intolerance, and diabetes. 
Overweight

Calle et al (2003) (M)

Calle et al (2003) (W)

Kuriyama et al (2005) (M)

Kuriyama et al (2005) (W)

Batty et al (2005) (M)

Oh et al (2005) (M)

Rapp et al (2005) (M)

N'Kontchou et al (2006) (M/W)

Samanic et al (2006) (M)

Summary estimate

\section{Obesity}

Møller et al (1994) (M)

Møller et al (1994) (W)

Wolk et al (2001) (M)

Wolk et al (2001) (W)

Nair et al (2002) (M/W )

Calle et al (2003) (M)

Calle et al (2003) (W)

Samanic et al (2004) (M, whites)

Samanic et al (2004) (M, blacks)

Batty et al (2005) (M)

Oh et al (2005) (M)

Rapp et al (2005) (M)

N'Kontchou et al (2006) (M/W)

Samanic et al (2006) (M)

Summary estimate

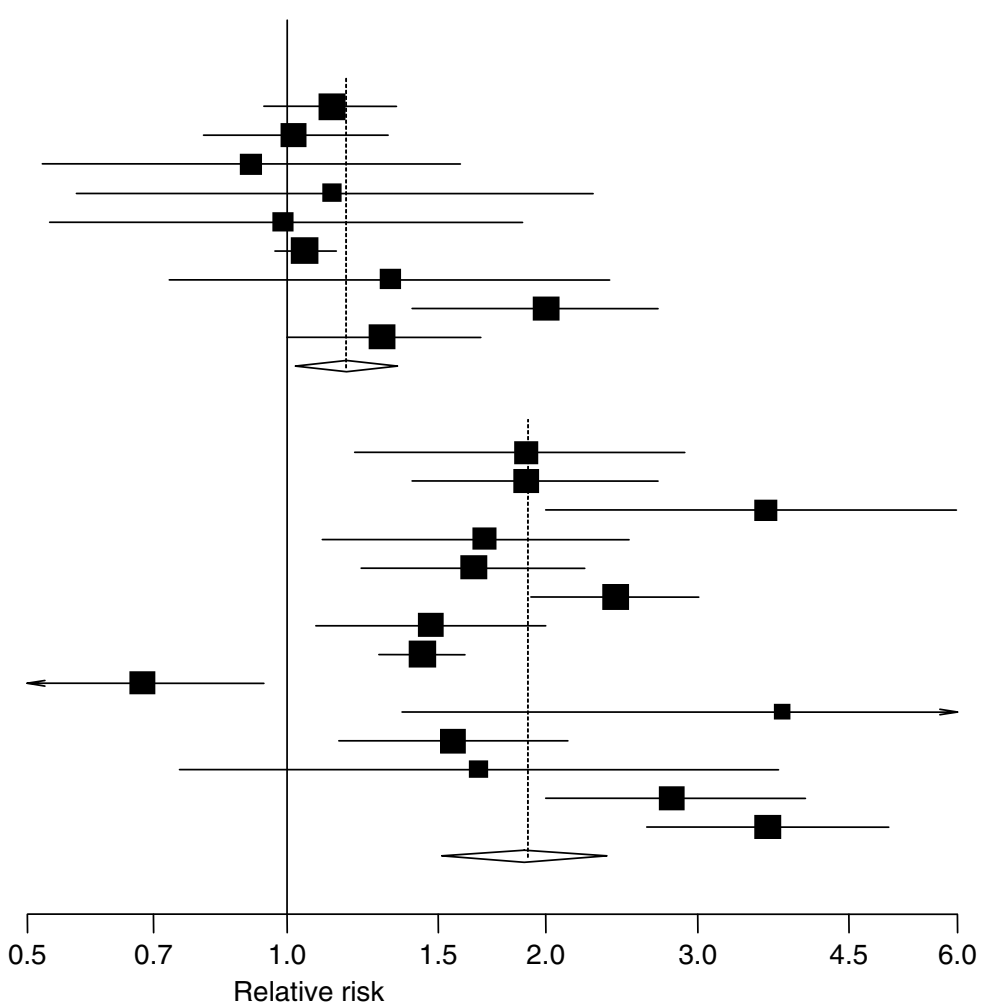

\section{Relative risk}

Relative risk

(95\% Cl)

$1.13(0.94-1.34)$

$1.02(0.80-1.31)$

$0.91(0.52-1.59)$

$1.13(0.57-2.27)$

$0.99(0.53-1.88)$

$1.05(0.97-1.14)$

$1.32(0.73-2.37)$

$2.00(1.40-2.70)$

$1.29(1.00-1.68)$

$1.17(1.02-1.34)$

$1.90(1.20-2.90)$

$1.90(1.40-2.70)$

$3.60(2.00-6.00)$

$1.70(1.10-2.50)$

$1.65(1.22-2.22)$

$2.41(1.92-3.01)$

$1.47(1.08-2.00)$

$1.44(1.28-1.61)$

$0.68(0.49-0.94)$

$3.76(1.36-10.4)$

$1.56(1.15-2.12)$

$1.67(0.75-3.72)$

$2.80(2.00-4.00)$

$3.62(2.62-5.00)$

$1.89(1.51-2.36)$

Figure I Relative risks of liver cancer associated with overweight and obesity. Relative risk estimates are for overweight and obese persons compared with normal weight persons. Tests for heterogeneity: overweight, $Q=16.83, P=0.03 ; I^{2}=52.5 \%$; obesity, $Q=88.03, P<0.00$ I; $I^{2}=86.4 \% . M=$ men; $\mathrm{W}=$ women

$1.37-2.03 ; n=3$ studies). There was no evidence for publication bias on the funnel plot (data not shown) or by Egger's test $(P=0.31$ for overweight and $P=0.21$ for obesity)

In a sensitivity analysis excluding the two studies that consisted of patients with cirrhosis (Nair et al, 2002; N'Kontchou et al, 2006), the summary relative risks were 1.07 (95\% CI: $1.01-1.15)$ for overweight and 1.85 (95\% CI: $1.44-2.37)$ for obesity. With stratification by assessment of obesity, the summary relative risks for the association between obesity and liver cancer were $2.15(95 \%$ CI: 1.66-2.77) for studies based on measured or self-reported weight and height (Nair et al, 2002; Calle et al, 2003; Batty et al, 2005; Oh et al, 2005; Rapp et al, 2005; N'Kontchou et al, 2006; Samanic et al, 2006) and 1.61 (95\% CI: 1.14-2.27) for studies based on a discharge diagnosis of obesity (Møller et al, 1994; Wolk et al, 2001; Samanic et al, 2004).

The PAR for excess body weight was calculated using the estimates of prevalence in the United States (Ogden et al, 2006) and the obtained summary relative risks of 1.17 and 1.89 for overweight and obesity, respectively. We estimated that $28 \%$ of liver cancer cases among men and $27 \%$ among women could be attributable to excess body weight $\left(\mathrm{BMI} \geqslant 25 \mathrm{~kg} \mathrm{~m}^{-2}\right)$.

\section{DISCUSSION}

This is the first meta-analysis on overweight and obesity in relation to liver cancer risk and it indicates that excess body weight is associated with increased risk. Summary results showed that the risk was 17 and $89 \%$ higher among persons who were overweight and obese, respectively, compared with those of normal weight. The relation between obesity and liver cancer seemed to be stronger in men than in women.

Although there was statistically significant heterogeneity among study results, the relation between obesity and risk of liver cancer was consistent. Differences in the relative risk estimates were largely in the magnitude rather than the direction of the association. All but 1 out of the 14 relative risk estimates for the association between obesity and liver cancer were above one (ranging from 1.44 to 3.76 ), and 12 of these estimates were statistically significant.

A potential limitation of this meta-analysis is that individual studies may have failed to control for potential known or unknown confounders. The most important risk factors for the development of liver cancer are chronic infections with hepatitis $\mathrm{B}$ virus and hepatitis $\mathrm{C}$ virus. Heavy, long-term alcohol consumption is also a risk factor (Yu and Yuan, 2004). None of the studies adjusted for hepatitis B or C virus infections, and only three (Calle et al, 2003; Kuriyama et al, 2005; Oh et al, 2005) controlled for alcohol intake. It is unlikely, however, that these risk factors are strongly related to body weight and entirely explain the observed relationship between excess body weight and liver cancer risk. Another limitation is that we could not examine whether the association between excess body weight and liver cancer was modified by hepatitis virus infections and alcohol intake because the studies included in this meta-analysis did not provide results stratified by these factors.

As this meta-analysis was based on published studies, possible publication bias could have affected the results. However, neither funnel plots nor formal statistical tests showed evidence for publication bias.

The observed increased risk of liver cancer associated with excess body weight may be mediated through the development of non-alcoholic fatty liver disease (NAFLD), a chronic liver disease that occurs in non-drinkers. NAFLD is characterized by a spectrum of liver tissue changes, ranging from accumulation of fat in the liver to non-alcoholic steatohepatitis (NASH), cirrhosis, and liver cancer at the most extreme end of the spectrum. Up to $90 \%$ of obese individuals have some degree of fatty liver, and approximately $25-30 \%$ have NASH (Neuschwander-Tetri and Caldwell, 2003). 
In summary, this meta-analysis supports evidence of an increased risk of liver cancer among overweight and obese persons. These findings indicate that liver cancer may, in part, be prevented by maintaining a healthy body weight.

\section{REFERENCES}

Batty GD, Shipley MJ, Jarrett RJ, Breeze E, Marmot MG, Smith GD (2005) Obesity and overweight in relation to organ-specific cancer mortality in London (UK): findings from the original Whitehall study. Int $J$ Obes (Lond) 29: 1267-1274

Calle EE, Rodriguez C, Walker-Thurmond K, Thun MJ (2003) Overweight, obesity, and mortality from cancer in a prospectively studied cohort of US adults. $N$ Engl J Med 348: $1625-1638$

Coleman MP, Gatta G, Verdecchia A, Esteve J, Sant M, Storm H, Allemani C, Ciccolallo L, Santaquilani M, Berrino F (2003) EUROCARE-3 summary: cancer survival in Europe at the end of the 20th century. Ann Oncol 14(Suppl 5): v128-v149

DerSimonian R, Laird N (1986) Meta-analysis in clinical trials. Control Clin Trials 7: $177-188$

Egger M, Davey Smith G, Schneider M, Minder C (1997) Bias in metaanalysis detected by a simple, graphical test. BMJ 315: 629-634

El-Serag HB, Mason AC (2000) Risk factors for the rising rates of primary liver cancer in the United States. Arch Intern Med 160: $3227-3230$

Hassan MM, Frome A, Patt YZ, El-Serag HB (2002) Rising prevalence of hepatitis $\mathrm{C}$ virus infection among patients recently diagnosed with hepatocellular carcinoma in the United States. J Clin Gastroenterol 35: $266-269$

Higgins JP, Thompson SG (2002) Quantifying heterogeneity in a metaanalysis. Stat Med 21: 1539-1558

IARC (2002) IARC handbooks of cancer prevention. Weight control and physical activity. Vol. 6, Lyon, France: IARC Press

Kuriyama S, Tsubono Y, Hozawa A, Shimazu T, Suzuki Y, Koizumi Y, Ohmori K, Nishino Y, Tsuji I (2005) Obesity and risk of cancer in Japan. Int J Cancer 113: 148-157

Larsson SC, Orsini N, Wolk A (2007) Body mass index and pancreatic cancer risk: A meta-analysis of prospective studies. Int J Cancer 120: $1993-1998$

Larsson SC, Wolk A (2006) Epidemiology of obesity and diabetes: prevalence and trends. In Obesity and Diabetes, Mantzoros C (ed) pp 15 - 36. Boston: Humana Press

Larsson SC, Wolk A (2007) Obesity and the risk of gallbladder cancer: a meta-analysis. Br J Cancer 96: 1457-1461

Møller H, Mellemgaard A, Lindvig K, Olsen JH (1994) Obesity and cancer risk: a Danish record-linkage study. Eur J Cancer 30A: 344-350

\section{ACKNOWLEDGEMENTS}

This work was supported by grants from the Swedish Cancer Society.

Nair S, Mason A, Eason J, Loss G, Perrillo RP (2002) Is obesity an independent risk factor for hepatocellular carcinoma in cirrhosis? Hepatology 36: $150-155$

Neuschwander-Tetri BA, Caldwell SH (2003) Nonalcoholic steatohepatitis: summary of an AASLD Single Topic Conference. Hepatology 37: $1202-1219$

N'Kontchou G, Paries J, Htar MT, Ganne-Carrie N, Costentin L, GrandoLemaire V, Trinchet JC, Beaugrand M (2006) Risk factors for hepatocellular carcinoma in patients with alcoholic or viral $\mathrm{C}$ cirrhosis. Clin Gastroenterol Hepatol 4: $1062-1068$

Ogden CL, Carroll MD, Curtin LR, McDowell MA, Tabak CJ, Flegal KM (2006) Prevalence of overweight and obesity in the United States, 19992004. JAMA 295: $1549-1555$

Oh SW, Yoon YS, Shin SA (2005) Effects of excess weight on cancer incidences depending on cancer sites and histologic findings among men: Korea national health insurance corporation study. J Clin Oncol 23: $4742-4754$

Parkin DM, Bray F, Ferlay J, Pisani P (2005) Global cancer statistics, 2002. CA Cancer J Clin 55: 74-108

Rapp K, Schroeder J, Klenk J, Stoehr S, Ulmer H, Concin H, Diem G, Oberaigner W, Weiland SK (2005) Obesity and incidence of cancer: a large cohort study of over 145000 adults in Austria. Br J Cancer 93: $1062-1067$

Ries LAG, Harkins D, Krapcho M, Mariotto A, Miller AB, Feuer EJ, Clegg L, Eisner MP, Horner MJ, Howlader N, Hayat M, Hankey BF, Edwards BK (2006) SEER cancer statistics review, 1975-2003. Bethesda, MD: National Cancer Institute, 2006 http://seer.cancer.gov/csr/1975_2003/ (accessed 30 June 2007)

Samanic C, Chow WH, Gridley G, Jarvholm B, Fraumeni JF (2006) Relation of body mass index to cancer risk in 362552 Swedish men. Cancer Causes Control 17: $901-909$

Samanic C, Gridley G, Chow WH, Lubin J, Hoover RN, Fraumeni Jr JF (2004) Obesity and cancer risk among white and black United States veterans. Cancer Causes Control 15: 35-43

Wolk A, Gridley G, Svensson M, Nyren O, McLaughlin JK, Fraumeni JF, Adam HO (2001) A prospective study of obesity and cancer risk (Sweden). Cancer Causes Control 12: 13-21

Yu MC, Yuan JM (2004) Environmental factors and risk for hepatocellular carcinoma. Gastroenterology 127: S72-S78 